\title{
Inhibition of glucose assimilation in Auxenochlorella protothecoides by light
}

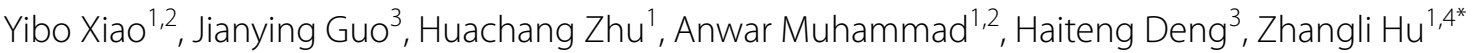 \\ and Qingyu $\mathrm{Wu}^{1,3^{*}}$
}

\begin{abstract}
Background: The yield of microalgae biomass is the key to affect the accumulation of fatty acids. A few microalgae can assimilate organic carbon to improve biomass yield. In mixotrophic cultivation, microalgae can use organic carbon source and light energy simultaneously. The preference of the main energy source by microalgae determines the biomass yield. Auxenochlorella protothecoides is an oleaginous mixotrophic microalga that can efficiently assimilate glucose and accumulate a large amount of biomass and fatty acids. The current study focused on the effect of light on the growth and glucose assimilation of A. protothecoides.
\end{abstract}

Results: In this study, we found that the uptake and metabolism of glucose in A. protothecoides could be inhibited by light, resulting in a reduction of biomass growth and lipid accumulation. We employed comparative proteomics to study the influence of light on the regulation of glucose assimilation in A. protothecoides. Proteomics revealed that proteins involving in gene translation and photosynthesis system were up-regulated in the light, such as ribulosephosphate 3-epimerase and phosphoribulokinase. Calvin cycle-related proteins were also up-regulated, suggesting that light may inhibit glucose metabolism by enhancing the production of glyceraldehyde-3-phosphate (G3P) in the Calvin cycle. In addition, the redox homeostasis-related proteins such as thioredoxin reductase were up-regulated in the light, indicating that light may regulate glucose uptake by changing the redox balance. Moreover, the increase of NADH levels and redox potential of the medium under illumination might inhibit the activity of the glucose transport system and subsequently reduce glucose uptake.

Conclusions: A theoretical model of how glucose assimilation in A. protothecoides is negatively influenced by light was proposed, which will facilitate further studies on the complex mechanisms underlying the transition from autotrophy to heterotrophy for improving biomass accumulation.

Keywords: Microalgae, Heterotrophic cultivation, Glucose assimilation, Biomass, Comparative proteomics

\section{Background}

Most microalgae are photoautotrophic microorganisms that need light as an energy source and carbon dioxide as carbon source to ultimately synthesize valuable products, such as polyunsaturated fatty acids (PUFAs), carotenoids,

\footnotetext{
*Correspondence: huzl@szu.edu.cn; qingyu@tsinghua.edu.cn ${ }^{1}$ Guangdong Technology Research Center for Marine Algal Bioengineering, Guangdong Key Laboratory of Plant Epigenetics, College of Life Sciences and Oceanography, Shenzhen University, Shenzhen 518060, People's Republic of China

Full list of author information is available at the end of the article
}

proteins, etc. [1]. Nevertheless, several microalgal species are capable of growing heterotrophically by assimilating sugars, exhibiting metabolic adaptability and flexibility. Prominent examples of such mixotrophic species include Prochlorococcus sp. [1], Auxenochlorella protothecoides (Synonym as Chlorella protothecoides) [2, 3], Chlorococcum sp. GD [4], and Chlorella zofingiensis [5]. The yield of value-added metabolites from microalgae depends on the intracellular content of metabolites and the biomass yield. Consequently, increasing biomass accumulation is a central strategy for increasing the yield of target 
products. The cultivation of mixotrophic microalgae in heterotrophic mode can increase the concentration of biomass by as much as 25 -fold compared with photoautotrophic cultivation [6]. Moreover, mixotrophic organisms are capable of photosynthesizing and assimilating organic carbon, which also significantly increases biomass productivity [7]. Genetic engineering of mixotrophs to improve their utilization of exogenous glucose by introducing heterologous glucose transporters was achieved in Phaeodactylum tricornutum [8] and Synechococcus elongatus PCC 7942 [9]. The utilization of sugars is essential for the heterotrophic growth mode of mixotrophic microalgae. The oxidation of sugars in heterotrophic and mixotrophic metabolic modes provides an increased supply of energy and metabolic precursors, allowing for faster cell growth and continuous production of target chemicals.

Auxenochlorella protothecoides is a typical oleaginous microalga with a great potential application value in the production of biodiesel and lutein [10-12]. In the heterotrophic mode under dark and nitrogen-depleted conditions, $A$. protothecoides can use glucose efficiently by utilizing at least nine glucose transporters [13]. A. protothecoides can transition between heterotrophy and photoautotrophy in response to light/dark and the $\mathrm{C} / \mathrm{N}$ ratio changes [14], and, thus, has multiple metabolic pathways that can be adapted for the manufacture of valuable products. Previous reports indicated that mixotrophic cultivation of $A$. protothecoides allows for higher biomass production than heterotrophic cultivation $[15,16]$. Under appropriate conditions of illumination and nutrient availability, $A$. protothecoides can also grow mixotrophically, simultaneously utilizing photosynthesis and heterotrophy. Light plays an important role in the regulation of enzymes involved in photosynthesis and is also the critical signal for the switch from heterotrophic to autotrophic growth in microalgae or in the post-germinative development of higher plants [17-20]. Conversely, the availability of glucose was found to affect photosynthesis in mixotrophs. Accordingly, high concentrations of glucose $(6-10 \mathrm{~g} / \mathrm{L})$ not only improved biomass accumulation but also inhibited photosynthesis $[4,10]$. However, the effect of photosynthesis on glucose utilization in microalgae is understudied.

In this study, we aimed to gain insights into the influence of light on glucose uptake and metabolism. Therefore, a comparative 2D LC-MS/MS analysis was performed to reveal the differences in the protein expression profile between $A$. protothecoides cultured in the presence of glucose under light and dark conditions. This comparison allowed us to identify the differentially abundant proteins involved in glucose metabolism and photosynthesis. Additionally, the redox state of the cells is known to be an important signal in higher plants. For example, the activity of the SUT1 protein from potato (Solanum tuberosum, StSUT1) is regulated by redox conditions during the day/night (light/dark) cycles which regulate the circadian clock [21]. We compared the redox state inside and outside of cells under light and dark conditions. Taken together, this study provides new insights into the influence of light on glucose transport and metabolism. Finally, we developed a tentative model of how light regulates glucose assimilation, which will facilitate further study on the heterotrophic transition in microalgae for enhancing biomass accumulation.

\section{Results and discussion}

\section{The differences in glucose assimilation under light and dark conditions}

The $A$. protothecoides was cultured in a $100-\mathrm{mL}$ shake flask using conventional nitrogen-limited heterotrophic medium. The experimental group was placed under light (mixotrophic culture-MC) and the control group was placed in the dark (heterotrophic culture-HC). The biomass and residual glucose concentration in the medium were measured to compare the growth and glucose consumption of the cultures. As shown in Fig. 1a, the growth of the $\mathrm{MC}$ was slower than that of the $\mathrm{HC}$, which depleted glucose on the 5th day. By contrast, glucose was not exhausted on the 7th day in the MC (Fig. 1b). The residual glucose concentration in the $\mathrm{MC}$ was higher than in the $\mathrm{HC}$, indicating that $A$. protothecoides assimilated less glucose in the light. Many microalgae, such as Phaeodactylum tricornutum, Chlorella vulgaris and Chlorococcum sp. GD, can use glucose when grown in light $[22,23]$. When such organisms are grown in illuminated mixotrophic culture, the biomass will be higher due to the concomitant activity of both photosynthesis and organic carbon assimilation. Therefore, the phenotype of A. protothecoides of reduced growth and glucose assimilation in the light is different from other microalgae. The specific cell growth rates of $A$. protothecoides cells in autotrophic and heterotrophic mode were found to be 0.0028 and $0.0257 \mathrm{~h}^{-1}$, respectively [24]. The specific cell growth rate in heterotrophic mode was 9 times higher than in autotrophic mode, indicating that carbon fixation via photosynthesis contributed less to the increase of biomass when both light and glucose were present.

Nitrogen is an essential element for chlorophyll and protein synthesis. Consequently, a sufficient supply of nitrogen sources can promote photosynthesis in microalgae [25]. After increasing the concentration of the nitrogen source to a high level (e.g., $5 \mathrm{~g} / \mathrm{L}$ glycine), the growth rate and glucose consumption were also reduced under illumination (Fig. 1c, d). The chlorophyll content was highest in the light with 5 -g/L glycine, while the cells 

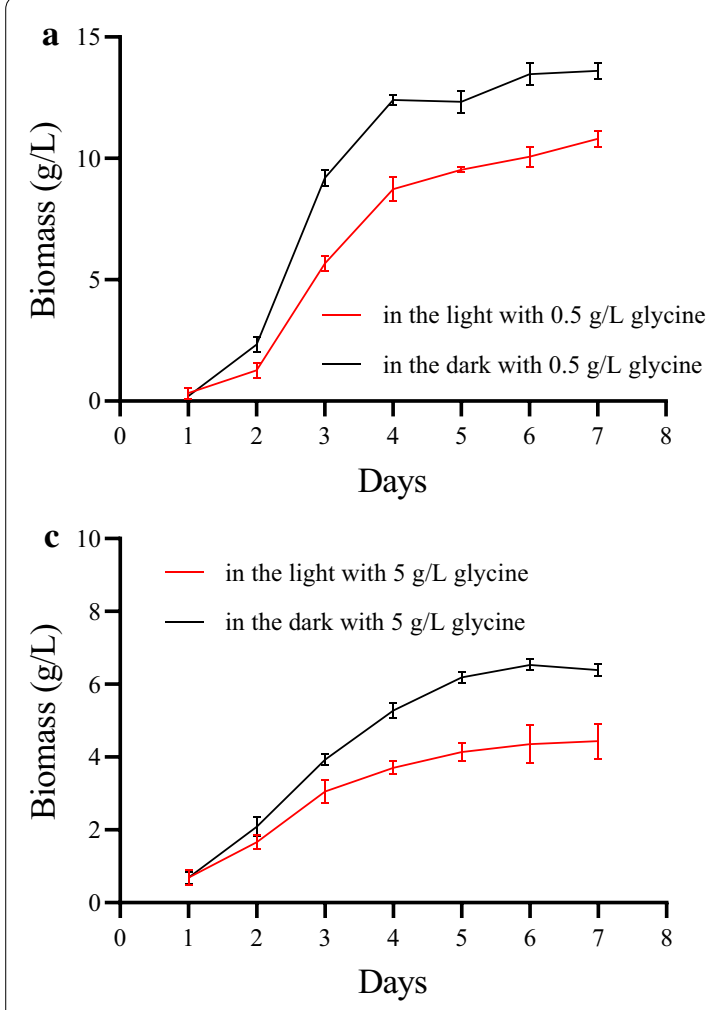

e

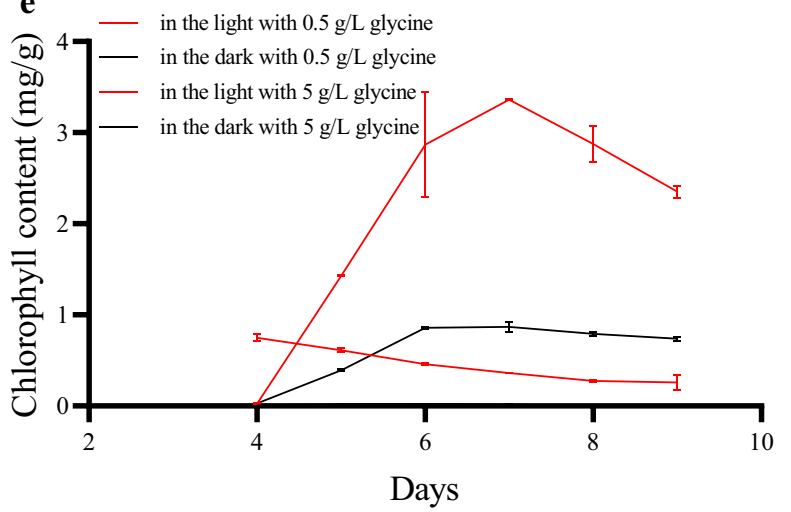

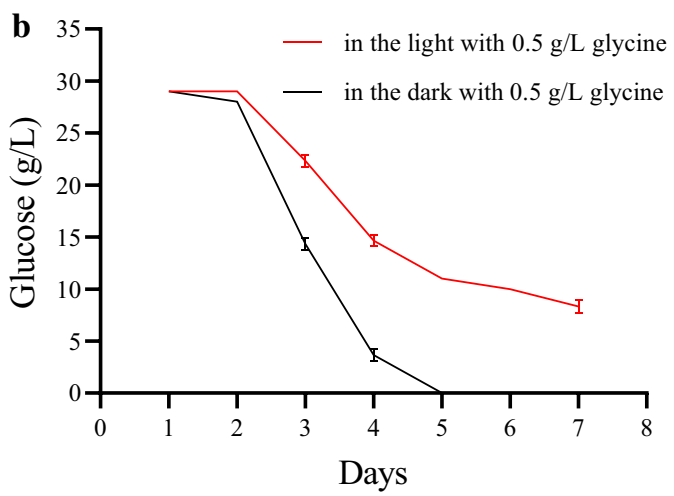

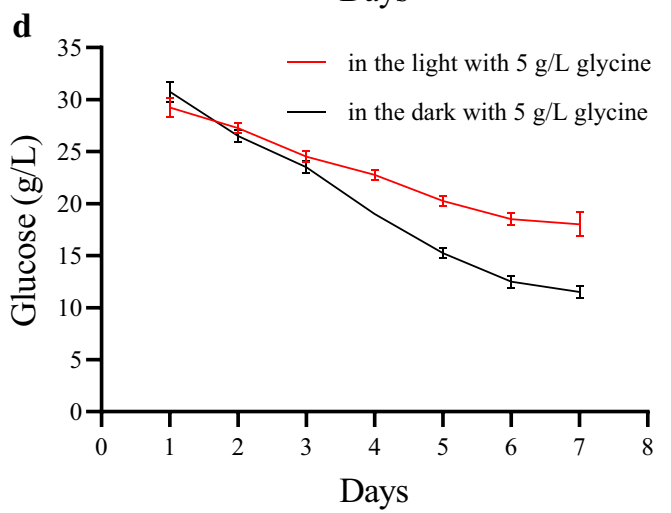

f

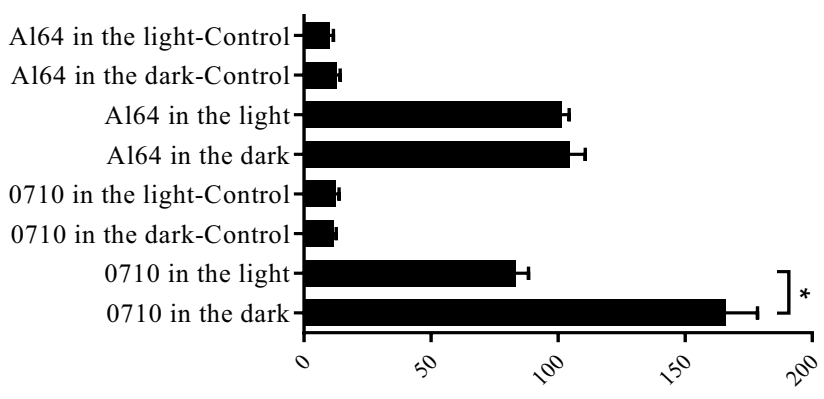

$\left[{ }^{3} \mathrm{H}\right] \mathrm{D}$-glucose radioactivity $(\mathrm{cpm})$

Fig. 1 Time curves of growth, glucose consumption and glucose transport ability under different culture conditions. a Biomass accumulation under the light and dark conditions with $0.5-\mathrm{g} / \mathrm{L}$ glycine; $\mathbf{b}$ concentration of residual glucose under the light and dark conditions with $0.5-\mathrm{g} / \mathrm{L}$ glycine; $\mathbf{c}$ biomass accumulation under the light and dark conditions with 5-g/L glycine; $\mathbf{d}$ concentration of residual glucose under the light and dark conditions with 5-g/L glycine; e chlorophyll content under the light and dark conditions with 0.5- and 5-g/L glycine; $\mathbf{f}$ comparison of the glucose transport ability of A. protothecoides 0710 and the photosynthesis-deficient mutant Al64 under light and dark conditions. Glucose uptake by microalgae cells was assayed at 4 days of cultivation in the light or dark. Microalgae cells without adding $\mathrm{D}_{-}\left[\mathrm{C}_{-}{ }^{3} \mathrm{H}\right]$ glucose was used as a negative control (in the light control/ in the dark control)

contained almost no chlorophyll in the dark with $0.5-\mathrm{g} / \mathrm{L}$ glycine (Fig. 1e). Furthermore, cells grown in the dark with $5-\mathrm{g} / \mathrm{L}$ glycine and in the light with $0.5-\mathrm{g} / \mathrm{L}$ glycine had low levels of chlorophyll. The chlorophyll content under high nitrogen source concentrations was significantly higher than under low nitrogen, but the growth rate and glucose consumption observed at the high nitrogen source concentration was also inhibited by light. Therefore, the reduced accumulation of biomass and inhibition of glucose consumption in the light was not simply caused by the photosynthetic fixation of carbon dioxide.

Auxenochlorella protothecoides can efficiently import glucose from the medium via a specific glucose 
transporter system. Gao et al. identified nine transporter homologs in $A$. protothecoides using the HUPs $\left(\mathrm{H}^{+} /\right.$hexose co-transporter) from Chlorella kessleri as the query sequence [13]. Moreover, three of the identified HUPlike proteins might be responsible for the ability of $A$. protothecoides to rapidly import glucose. Radiolabelled substrate can be used to measure the rate of sugar transport and the ability of sugar uptake more accurately. The sucrose transporter StSUT1 from potato (Solanum tuberosum) was expressed in yeast and the transport activity and post-translational modification of StSUT1 were measured using ${ }^{14} \mathrm{C}$-Sucrose [21]. Unlike the tissues of higher plants, the unicellular $A$. protothecoides can be directly used to measure the glucose transport rate in vivo. A. protothecoides Al64 is an autotrophy-deficient strain obtained by ethyl methanesulfonate mutagenesis. The glucose transport activity of wild-type $A$. protothecoides and Al64 was measured using radiolabelled D- $\left[2-{ }^{3} \mathrm{H}\right]$ glucose. In Fig. 1f, the $\mathrm{X}$ coordinate represents the radioactivity generated by $\mathrm{D}-\left[2-{ }^{3} \mathrm{H}\right]$ glucose, which had been transported into cells within $3 \mathrm{~min}$. This value reflects the glucose transport rate. The results showed that the glucose transport rate of wild-type cells in the dark was almost two times higher than under illumination $(p=0.013<0.05)$, indicating that light could inhibit the glucose transport. By contrast, there was no significant difference in Al64 under the light and dark conditions. Hence, the glucose transport activity of Al64 was not affected by light, indicating that the inhibition of the glucose transport activity of $A$. protothecoides by light is related to the photosynthesis system and may be adjusted by changes in the intracellular environment.

The lipid content of $A$. protothecoides cells grown in heterotrophic mode four times higher (55.20\%) than in the autotrophic mode [12]. The heterotrophically grown cells were filled with large lipid droplets, while the lipid droplets in the autotrophically grown cells were smaller and fewer [26]. Subsequently, the differences of subcellular structure between cells from the $\mathrm{MC}$ and the $\mathrm{HC}$ were observed by TEM (Additional file 1: Figure S1). The structure of chloroplasts was not found in cells from the $\mathrm{HC}$, while incomplete chloroplast structure was observed in cells from the $\mathrm{MC}$, indicating that the structure of chloroplast was still retained under nitrogen limitation condition combined with illumination. The efficiency of PSII (ФPSII) of $A$. protothecoides in the $\mathrm{MC}$ and $\mathrm{HC}$ was detected (Additional file 1: Figure S2). The results suggested $\Phi$ PSII of $A$. protothecoides was rarely determined in the dark. Notably, ФPSII of MC was increased after 4 days of cultivation. It is suggested that incomplete chloroplast structures of $A$. protothecoides still have photosynthesis ability. The diameter of lipid droplet was larger than $2 \mu \mathrm{m}$ in cells from the $\mathrm{HC}$ and smaller than $2 \mu \mathrm{m}$ in those from the MC. The differences of starch, lipid and protein contents between cells from the $\mathrm{HC}$ and the $\mathrm{MC}$ were measured (Fig. 2). The starch and lipid contents of the $\mathrm{MC}$ were lower than that of the $\mathrm{HC}$, indicating that lipid accumulation was inhibited under illumination (Fig. 2a, b). The protein contents of the $\mathrm{MC}$ were significantly higher than that of the $\mathrm{HC}$ $(p<0.05)$ (Fig. 2c). This may be due to the photosynthetic system requiring more proteins in the $\mathrm{MC}$ than $\mathrm{HC}$. Under nitrogen limitation, most of the precursors for lipid biosynthesis were derived from extracellular glucose. The difference between lipid and protein accumulation between the $\mathrm{HC}$ and $\mathrm{MC}$ indicated that light also influenced glucose metabolism.

\section{Comparative proteomic analysis of A. protothecoides cells grown under illumination and in the dark}

Comparative proteomics was used to study the mechanism by which light regulates glucose uptake in $A$. protothecoides. Protein samples were labeled with TMT, identified by tandem mass spectrometry, and analyzed using the $A$. protothecoides protein database. A total of 4820 proteins were identified in the samples, accounting
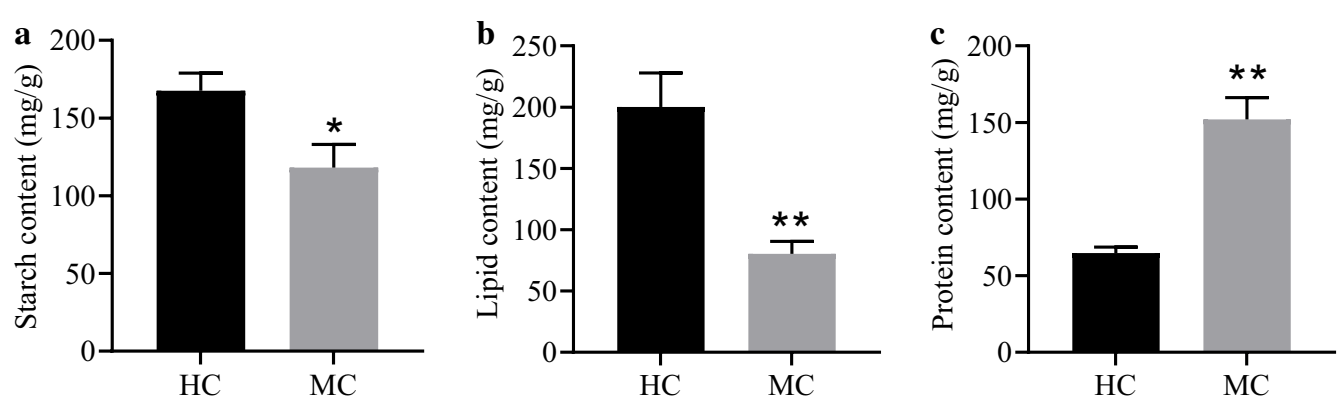

Fig. 2 Cell components of A. protothecoides from heterotrophic culture $(\mathrm{HC})$ and mixotrophic culture $(\mathrm{MC})$. a Starch content of A. protothecoides. $\mathbf{b}$ Lipid content of $A$. protothecoides. $\mathbf{c}$ Protein content of $A$. protothecoides 
for $68.5 \%$ of the total known proteins of $A$. protothecoides. The proteins with ratios greater than 1.3 or lower than 0.77 and $p$-values of less than 0.05 were identified as the differentially expressed proteins (DEPs) between the $\mathrm{HC}$ and MC. A total of 240 up- and 98 downregulated proteins were identified (Additional file 2: Table S1, S2).

The online functional annotation tool DAVID was used to analyze the up- and downregulated proteins separately [27]. The downregulated proteins were grouped into 3 clusters (Fig. 3a). The proteins in Cluster1 (Enrichment Score: 3.45$)$ were mainly related to the biosynthesis and metabolism of lipids and fatty acids, which was consistent with the observed smaller lipid droplets in the cells from the MC. The proteins in Cluster2 (Enrichment Score: 1.67) were identified as having a non-covalent interaction with flavin adenine dinucleotide (FAD), which is also involved in the metabolism of pyruvic acid, fatty acids, oxidative degradation of amino acids and the electron transport chain. Cluster3 (Enrichment Score: 0.004) included integral membrane proteins and transmembrane proteins.

The upregulated proteins were grouped into 8 clusters (Fig. 3b). Cluster1 (Enrichment Score: 4.58) contained many ribosomal proteins involved in the protein translation process. The upregulation of ribosomal proteins might be related to the increased requirements for proteins due to the construction of photosynthesis systems in the MC. The proteins of Cluster2 (Enrichment Score: 2.98) were associated with the photosynthesis system. It was shown that even under nitrogen-limited conditions (glycine concentration $=0.5 \mathrm{~g} / \mathrm{L}$ ), light could still promote the construction of the photosynthesis system. Cluster3 (Enrichment Score: 1.26) included iron-sulfur proteins and metal-binding proteins. Most proteins in this cluster were related to the electron transport chain of photosynthesis, indicating that the photosynthetic electron transport chain became active. Cluster4 (Enrichment Score: 1.2) was also related to photosynthesis. Importantly, all of the four clusters were consistent with the observed phenotypes, indicating that A. protothecoides needs to synthesize more proteins in MC to construct the photosynthetic system. Cluster 5 (Enrichment Score: 0.62 ) included proteins with sulfide oxidoreductase activity and those involved in intracellular redox balance. Thiol-disulfide exchange reduction/oxidation (redox) reactions regulate carbon fixation, respiration, and metabolic processes in plant cells [28]. The redox system plays a key role in maintaining cellular homeostasis and regulating cell growth and metabolism [29]. Under illumination, the redox homeostasis-related proteins in A. protothecoides were upregulated, indicating a change in intracellular redox balance. Hence, the redox balance was changed by light, and the change of cell homeostasis provided new clues for studying the influence of light on glucose assimilation. The enrichment scores of clusters 6 , 7 , and 8 were, respectively, only $0.37,0.35$ and 0.15 , indicating that the enrichment of protein functions in these three clusters was poor.

Since A. protothecoides and Chlamydomonas reinhardtii are closely related, the protein-protein interaction (PPI) database of $C$. reinhardtii from STRING was used to analyze the interaction relationships of DEPs of A. protothecoides based on homology alignment [30]. The DEPs in the PPI network numbered in accordance with the accession numbers of the proteins in the UniProt database (Fig. 3c). The different colors indicate that they were clustered according to similar functions or compositions. The red cluster contained the ribosome-associated proteins. The purple cluster was involved in carbon metabolism, indicating that light had an effect on carbon metabolism. Most proteins in the blue cluster were oxidoreductases. Proteins in the green cluster were enzymes associated with the tricarboxylic acid cycle. The purplered cluster contained proteins involved in the synthesis of lipids. A yellow cluster was associated with fatty acid metabolism. Proteins in the orange cluster were associated with chlorophyll synthesis. Importantly, the results of PPI network analysis were consistent with the results of DAVID analysis.

The DEPs indicated by gray circles were not clustered. The largest gray circle was A0A087SDG3, which had the most interactions with other ungrouped proteins. A0A087SDG3 was predicted to be a thioredoxin reductase, and it was upregulated. Thioredoxin reductase, thioredoxin and NADPH constitute the thioredoxin system, which plays an important role in maintaining the intracellular redox balance. Although thioredoxin reductase was not clustered in the PPI network, the number of interacting proteins reflects a wide range of effects on DEPs. Combined with the analysis of the upregulated proteins in Cluster5, the DEPs and PPI information all reflected the significant changes in the expression of proteins related to the redox balance under illumination. This suggested that the intracellular redox balance was affected by light and this effect was likely related to the observed regulation of glucose assimilation.

\section{Pathway mapping of DEPs in KEGG}

The DEPs were uploaded to KEGG Mapper for pathway enrichment, whereby the upregulated proteins were marked in red and the downregulated proteins were marked in blue [31]. The annotated proteins in the $A$. protothecoides genome were marked in green. According to the phenotype of influencing glucose assimilation under illumination, KEGG pathway analysis focused on 


\begin{tabular}{|l|l}
\hline $\mathbf{a}$ & $\begin{array}{l}35.00 \% 7 \mathrm{GO} 00006633 \sim \text { fatty acid } \\
\text { biosynthetic process } \\
20.00 \% \text { 4 Lipid metabolism } \\
-15.00 \% \text { 3 Fatty acid biosynthesis } \\
15.00 \% \text { 3 Fatty acid metabolism } \\
15.00 \% \text { 3 Lipid biosynthesis }\end{array}$ \\
Cluster1 & Cluster2
\end{tabular}

b

$\begin{aligned}= & 21.43 \% 18 \text { Ribosomal protein } \\ & 21.43 \% 18 \text { Ribonucleoprotein } \\ & 19.05 \% 16 \mathrm{GO}: 0005840 \sim \text { ribosome } \\ & 19.05 \% 16 \mathrm{GO}: 0003735 \sim \text { structural constituent of ribosome } \\ \text { Cluster1 }= & 19.05 \% 16 \mathrm{GO}: 0006412 \sim \text { translation }\end{aligned}$

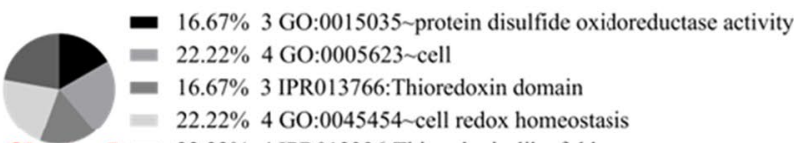

Cluster5 $=22.22 \% 4$ IPR012336:Thioredoxin-like fold

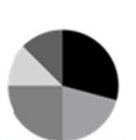

- $29.17 \% 7$ GO:0009654 photosystem II oxygen evolving complex

= 20.83\% 5 GO:0019898 extrinsic component of membrane

- 25.00\% 6 GO:0005509 calcium ion binding

- $12.50 \% 3$ IPR002683:Photosystem II PsbP, oxygen evolving comple

Cluster2 $=12.50 \% 3$ IPR016123:Mog1/PsbP, alpha/beta/alpha sandwich

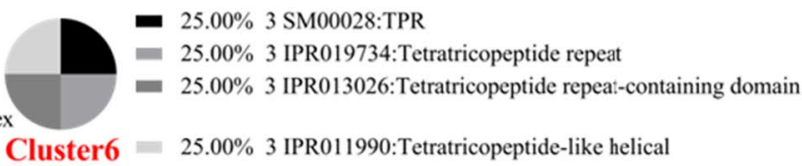

- $7.84 \% 4$ Iron-sulfur

$=9.80 \% 5 \mathrm{GO}: 0009055$ electron carrier activity

$5.88 \% 32 \mathrm{Fe}-2 \mathrm{~S}$

$=7.84 \% 4$ Electron transport

- $9.80 \% 5$ Iron

Cluster3 $=17.65 \% 9$ Metal-binding

- $5.88 \% 3$ GO:0051537 2 iron, 2 sulfur cluster binding

$9.80 \% 5 \mathrm{GO}: 0009535 \sim$ chloroplast thylakoid membrane

$=13.73 \% 7$ Transport

- $11.76 \%$ 6 GO:0046872 metal ion binding

- $21.21 \% 7$ Photosynthesis

- 15.15\% 5 GO:0009535 chloroplast thylakoid membrane

$12.12 \% 4$ Thylakoid

$18.18 \% 6$ Plastid

- $15.15 \% 5$ Chloroplast

Cluster4 $=18.18 \% 6$ GO:0046872 metal ion binding

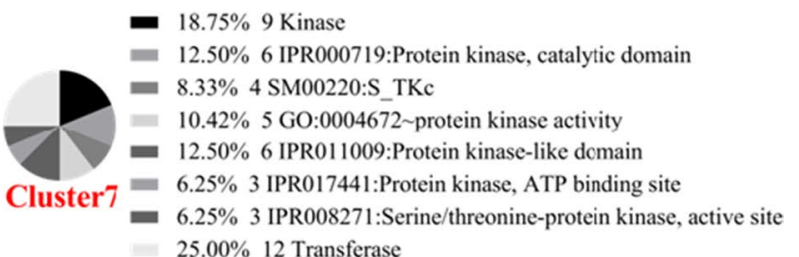

$27.08 \% 26$ Membrane

$23.96 \% 23$ Transmembrane

$22.92 \% 22$ Transmembrane helix

$26.04 \% 25$ GO:0016021 integral component of membrane

Cluster8

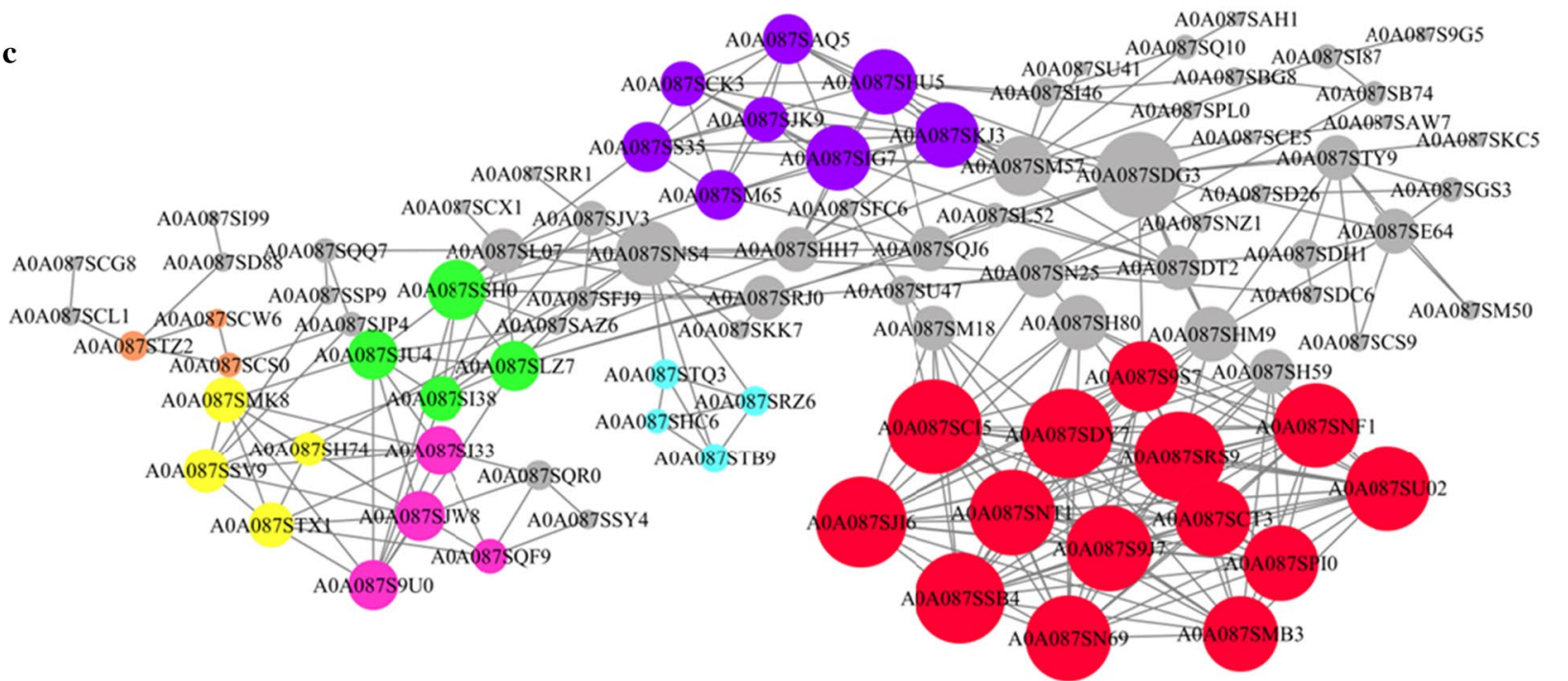

Fig. 3 Clustering of DEPs between MC cells and HC cells. a DAVID clustering of downregulated DEPs; b DAVID clustering of upregulated DEPs; $\mathbf{c}$ protein-protein interaction network of DEPs 
photosynthesis, glycolysis, fatty acid biosynthesis and carbon fixation.

There were obvious differences in the subcellular structure of cells from the $\mathrm{MC}$ and the HC. Chloroplastic structures were apparent in the cells form the MC. While these were not as distinct as in the autotrophically grown cells, they nevertheless indicated that there was active photosynthesis in the MC (Fig. 2). All proteins enriched in the photosynthesis pathway were upregulated, including subunits of photosystem I (PSI), photosystem II (PSII) and the cytochrome b6-f complex (Additional file 1: Figure S3). All top forty proteins were almost related to photosynthesis, indicating that light could promote the construction of the photosynthetic systems even under nitrogen-limited culture conditions. In addition to the constituent proteins of the photosystem reaction center, there were three oxygen-evolving enhancer proteins (OEE) among the top eight upregulated proteins. The upregulation fold changes of PsbO (OEE1), PsbP (OEE2) and PsbQ (OEE3) reached 8.09, 6.96, and 6.21, respectively. OEE is an important component of the oxygen-evolving complex (OEC) in PSII, which together with manganese clusters participates in the water splitting reaction to generate oxygen and electrons. Under $\mathrm{NaCl}$ - and heat-stress, the extended structure of OEE can protect the reaction center D1 protein from oxygen radicals $[32,33]$. Forster et al. found that two very high light (VHL)-resistant mutants of $C$. reinhardtii upregulated OEE1 expression under high light stress [34]. OEE was also found to have a thioredoxin-like activity in Chlorella [35]. Three OEE proteins were highly upregulated in MC, which could improve the function of intracellular OEC to maintain the activity of PSII and redox balance. Under nitrogen-limited conditions, the coexistence of glucose and light may be a stress factor for A. protothecoides cells. In response to stress, intracellular metabolism undergoes a series of adjustments that alter the accumulation of metabolites.

Light has an influence on glucose assimilation, including glucose transport and metabolism. Exogenous glucose first enters the glycolysis pathway to produce pyruvate (Fig. 4). Most of the DEPs in the glycolysis pathway were downregulated. Two enzymes that catalyze the production of D-glyceraldehyde 3-phosphate from D-glucose 6-phosphate, as well as pyruvate kinase were downregulated, which may eventually reduce the synthesis of pyruvate. The enzymes that are responsible for the producing acetyl-CoA from pyruvate, i.e., pyruvate dehydrogenase, dihydrolipoic acid dehydrogenase, dihydrothionyl dehydrogenase, acetaldehyde dehydrogenase, and acetylCoA synthase were also downregulated (Fig. 4), indicating a decrease in the synthesis of acetyl-CoA. Most of the enzymes that are involved in the fatty acid biosynthesis pathway were downregulated (Additional file 1: Figure S4). Acetyl-CoA is a precursor for fatty acid biosynthesis, and reduction of the biosynthesis of acetyl-CoA may be responsible for the decrease of fatty acid biosynthesis. The downregulation fold changes of citrate synthase and dihydrolipoyl dehydrogenase in TCA cycle were 0.75 and 0.66. Malate dehydrogenase was upregulated slightly. The downregulation of citrate synthase, which controls the initiation of TCA cycle, suggested a weakening of the TCA cycle, which might be one of the reasons for the reduced growth rate under illumination (Additional file 1: Figure S5).

The results showed that ribulose-phosphate 3-epimerase and phosphoribulokinase, which catalyze the production of ribulose bisphosphate (RuBP) in the carbon fixation pathway of photosynthetic organisms, were upregulated 1.55 and 3.56 times, respectively (Fig. 5). The RuBP carboxylase and glyceraldehyde-3-phosphate dehydrogenase in the Calvin cycle were upregulated 2.78 and 2.62 times, respectively, indicating that the synthesis of RuBP was increased and the Calvin cycle was also enhanced. In the Calvin cycle, $\mathrm{CO}_{2}$ is converted into G3P, which is also an intermediate product of glycolysis. Under illumination, the G3P produced by the Calvin cycle may promote the reverse reaction of fructose-bisphosphate aldolase in glycolysis, thereby inhibiting glucose metabolism. Therefore, light might inhibit the glucose metabolism via chemical products of the dark reaction of photosynthesis.

\section{Redox analysis of A. protothecoides under light and dark conditions}

Previous studies have shown that higher plants also undergo redox changes during the night and day, thereby regulating the activity of sucrose transporters [36]. Redox states integrate and coordinate the energy production and status within a cell to regulate homeostasis and metabolism [37]. The results obtained from the DAVID, PPI and KEGG analysis showed that the proteins involved in the redox system had significant differences, indicating that the redox state of $A$. protothecoides significantly changed under illumination. Accordingly, the redox properties inside and outside the cells were examined.

The $\mathrm{pH}$ value and oxidation-reduction potential (ORP) of the culture supernatant in $\mathrm{HC}$ and $\mathrm{MC}$ were measured using a $\mathrm{pH}$ meter. The ORP value reflects the relative degree of oxidative and reductive properties in the medium. A positive and higher ORP value indicates that it is an oxidative environment and has higher oxidative potential, respectively. As shown in Fig. 6, the $\mathrm{pH}$ of the $\mathrm{HC}$ gradually decreased, indicating that the acidity increased. At the same time, the ORP value gradually increased, indicating that the oxidative 


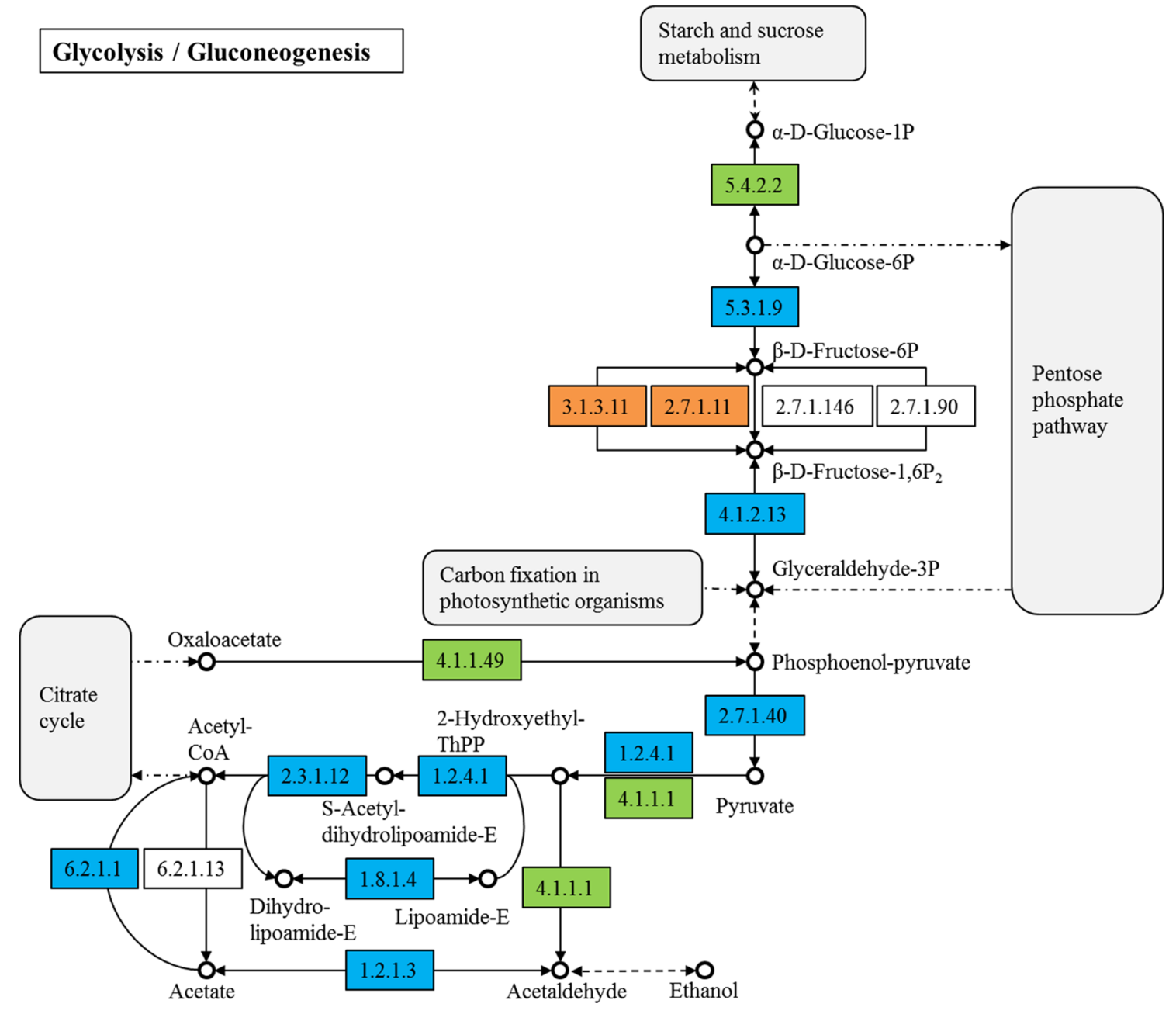

Fig. 4 DEPs in glucose metabolism

potential increased. While the $\mathrm{pH}$ of the $\mathrm{MC}$ also gradually decreased, its ORP value increased much less, showing that the oxidation potential of $\mathrm{MC}$ was not significantly increased. However, the ORP value was positive, indicating that both the $\mathrm{HC}$ and $\mathrm{MC}$ were in an oxidative environment; whereby, an increase of oxidation in the medium was prevented under light illumination. The improved glucose uptake of $A$. protothecoides in the dark might due to the stronger oxidative properties of the medium, which increased the activity of the glucose transport system.

Next, the intracellular $\mathrm{NAD}^{+}$and NADH levels were measured. The total amount of $\mathrm{NAD}^{+}$and NADH did not change significantly upon illumination (Fig. 6c). However, the ratio of NADH/NAD ${ }^{+}$and contents of $\mathrm{NADH}$ in the MC was higher than in the HC (Fig. 6d, e). These results showed that illumination affects the cellular homeostasis, which ultimately led to a more reductive intracellular environment. The high intracellular reduction state of the MC might reduce the activity of the glucose transport system. This was similar to the sucrose transporter activity in plant systems, which was lower in reductive environments [21,36]. Further research will be conducted.

\section{Conclusions}

In this study, we found that glucose assimilation in microalgae could be inhibited by light, resulting in a reduction of biomass growth and lipid accumulation. Comparative proteomic analysis revealed that three OEE proteins were significantly upregulated and the thioredoxin system was changed to balance the intracellular redox state. Furthermore, pathway analysis revealed that the G3P produced through the dark reaction of photosynthesis under illumination would 


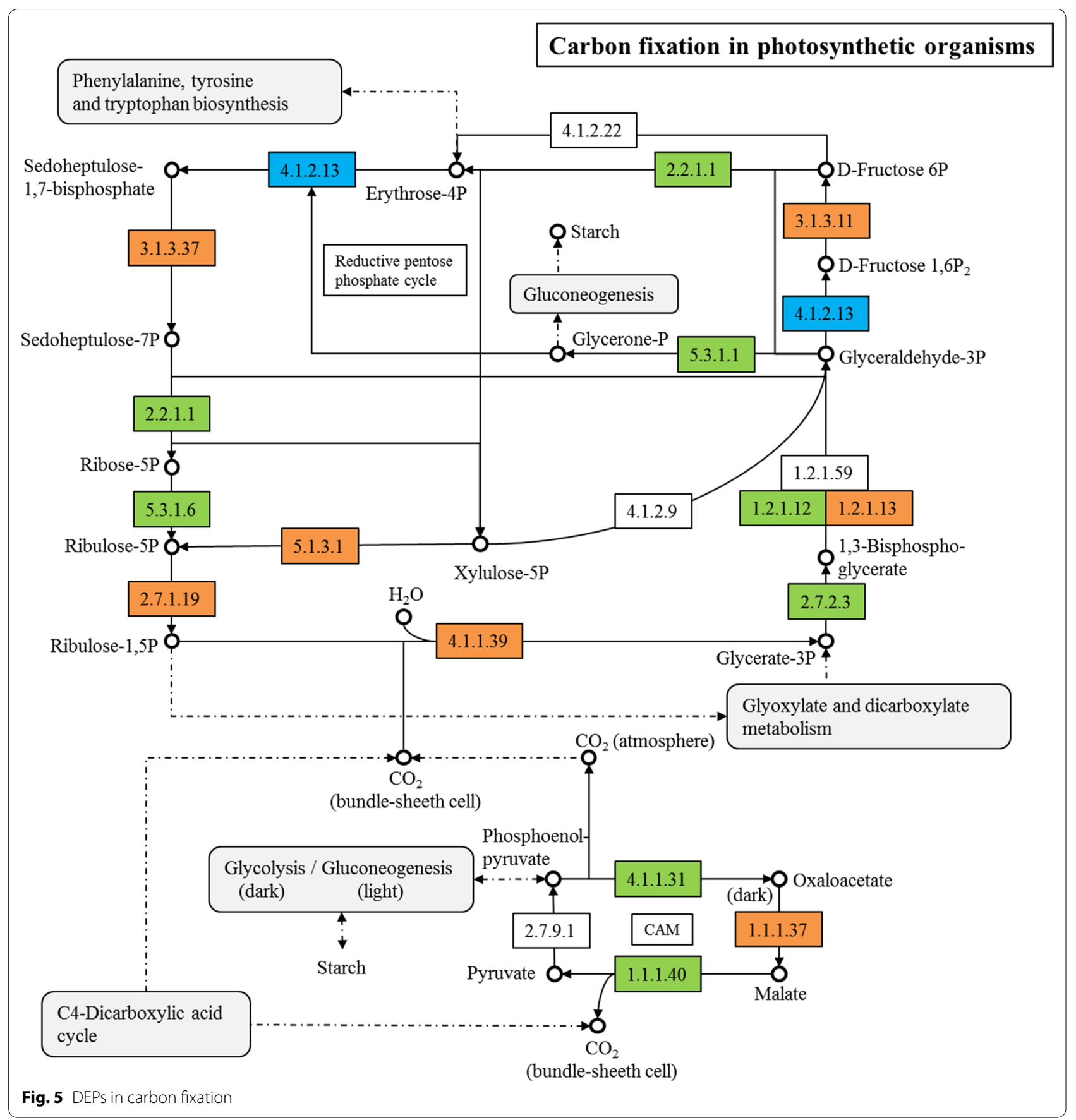

reverse the glycolysis pathway and inhibit glucose metabolism. The decrease of glucose transport activity might be related to the more reduced state of the intracellular and external environment. Finally, a theoretical model of how glucose assimilation in A. protothecoides is negatively influenced by light was firstly proposed in this study (Additional file 1: Figure S6).

\section{Methods}

\section{Strain and culture conditions}

Auxenochlorella protothecoides strain 0710 was obtained from the Culture Collection of Algae at the University of Texas (Austin, TX, USA) and screened for high lipid yield in the Algae Bioenergy Laboratory at Tsinghua University (Beijing, China). Auxenochlorella protothecoides strain Al64 was isolated from 0710 as a mutant 
$\mathbf{a}$
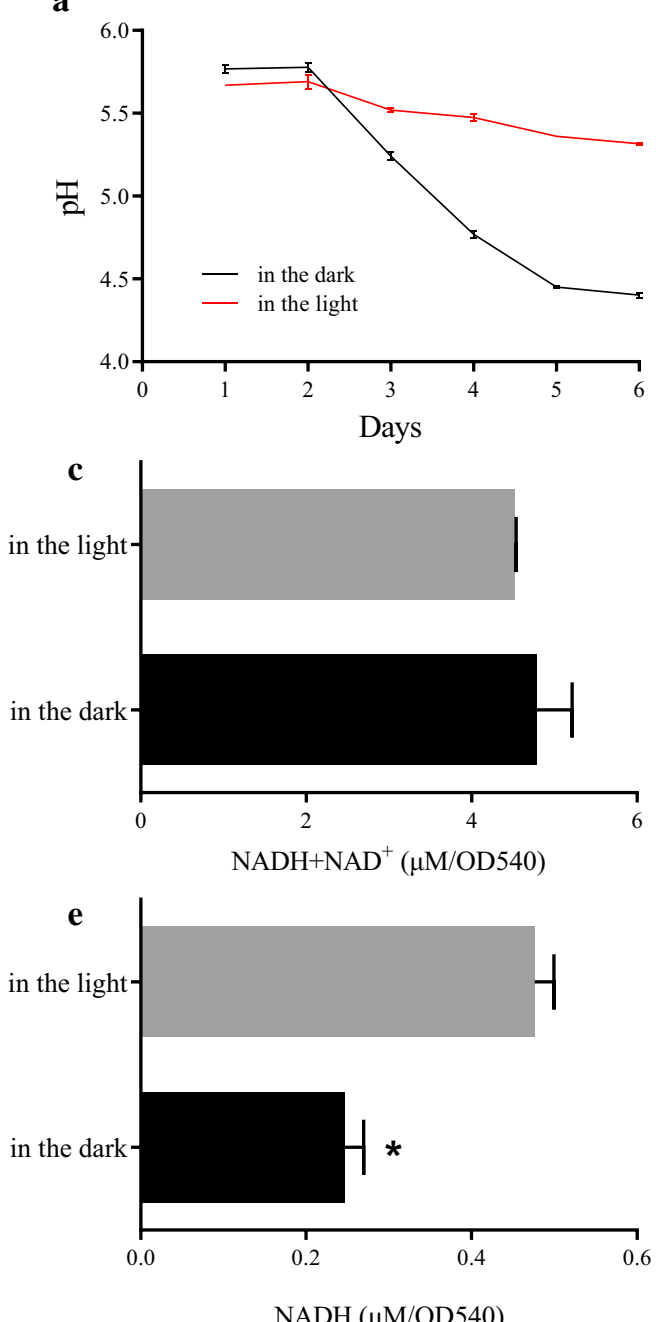

b

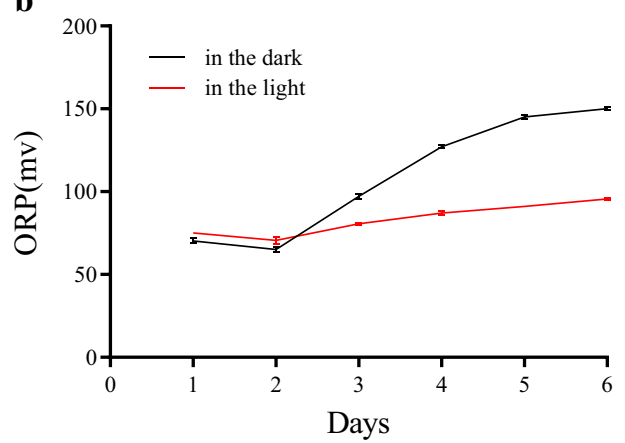

d
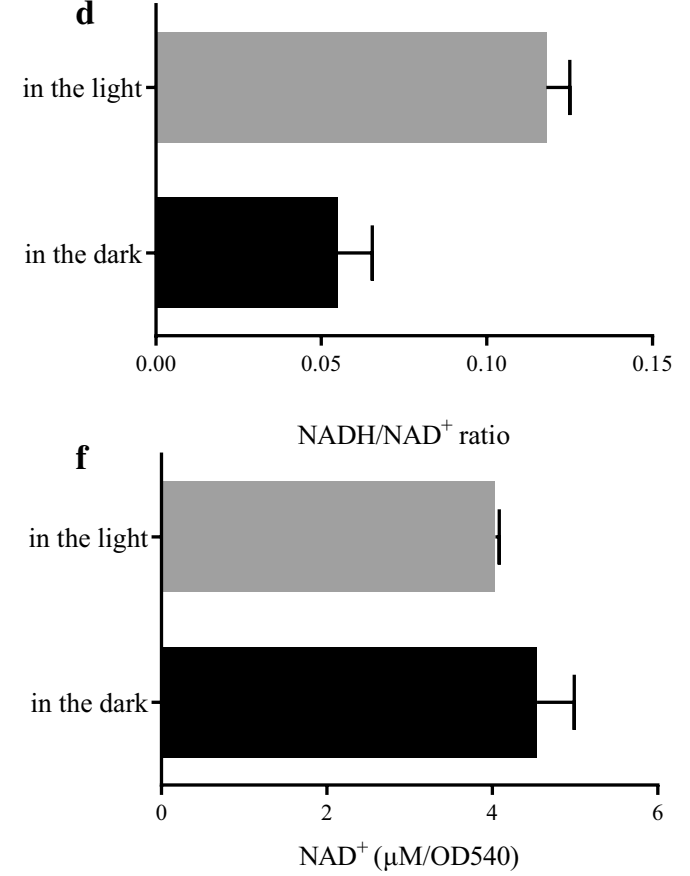

Fig. 6 Changes of $\mathrm{pH}, \mathrm{ORP}$ and $\mathrm{NAD}^{+} / \mathrm{NADH}$ levels under $\mathrm{MC}$ and $\mathrm{HC}$ conditions. $\mathbf{a}$ The $\mathrm{pH}$ of the medium under the light and dark conditions; $\mathbf{b}$ the ORP of the medium under the light and dark conditions; $\mathbf{c}$ total NADH and NAD ${ }^{+}$pools in the cells grown under the light and dark conditions; $\mathbf{d} \mathrm{NADH} / \mathrm{NAD}^{+}$ratios of cells grown under the light and dark conditions; e NADH amounts in the cells grown under the light and dark conditions; $\mathbf{f}$ $\mathrm{NAD}^{+}$amounts in the cells grown under the light and dark conditions

with autotrophy deficient. The cells were maintained in a basal medium containing (per liter): $0.7-\mathrm{g} \mathrm{KH}_{2} \mathrm{PO}_{4}, 0.3-\mathrm{g}$ $\mathrm{K}_{2} \mathrm{HPO}_{4}, 0.3-\mathrm{g} \mathrm{MgSO}_{4} \cdot 7 \mathrm{H}_{2} \mathrm{O}, 0.3-\mathrm{mg} \mathrm{FeSO}_{4} \cdot 7 \mathrm{H}_{2} \mathrm{O}, 0.01-$ $\mathrm{mg}$ thiamine, and 1-mL A5 trace mineral solution [12]. Glycine was selected as the nitrogen source in the study since it is more suitable nitrogen source than $\mathrm{NH}_{4} \mathrm{Cl}$ and urea for growth of $A$. protothecoides [10]. The nitrogenlimited medium was the basal medium with the addition of $30-\mathrm{g} / \mathrm{L}$ glucose and $0.5-\mathrm{g} / \mathrm{L}$ glycine [13]. The sufficient nitrogen medium was basal medium with the addition of 30-g/L glucose and 5-g/L glycine [19]. All media and the cultivation apparatus were sterilized with steam at $112^{\circ} \mathrm{C}$ and $0.12 \mathrm{MPa}$ for $30 \mathrm{~min}$.
The cells were grown in $100-\mathrm{mL}$ flasks on a shaker set at $220 \mathrm{rpm}$ and $28 \pm 1{ }^{\circ} \mathrm{C}$ for all cultivation modes. Mixotrophic culture (MC): cells were maintained in the nitrogen-limited medium under illumination of $2000 \mathrm{~lx}$. Heterotrophic culture (HC): cells were maintained in the nitrogen-limited medium under dark conditions.

\section{Determination of biomass, chlorophyll and glucose}

Samples comprising $1 \mathrm{~mL}$ of the microalgal cell suspension were harvested by centrifugation at $8000 \mathrm{rpm}$ for $5 \mathrm{~min}$ and the cell pellets were washed twice with distilled water, dried at $70{ }^{\circ} \mathrm{C}$ until constant weight, and weighed to determine the dry cell weight. Glucose concentrations 
were determined using an SBA-40C enzymatic bio-analyzer (Shandong Academy of Sciences, China).

The chlorophyll content was determined by measuring the absorbance of the methanol extracts at $666 \mathrm{~nm}$ as described before [38]. The chlorophyll fluorescence was determined as described in the previous report [39], using a PHYTO-PAM Phytoplankton Analyzer (Walz, Germany). The effective quantum yield of PSII (ФPSII) was determined as follows $\Phi$ PSII $=\left(\mathrm{Fm}^{\prime}-\mathrm{Fs}\right) / \mathrm{Fm}^{\prime}$.

Glucose uptake by cells was assayed as described before $[21,40]$. For each assay, $1-\mu \mathrm{Ci} \mathrm{D}-\left[2-{ }^{3} \mathrm{H}\right]$ glucose (specific radioactivity $21.5 \mathrm{Ci} \mathrm{mmol}^{-1}$; PerkinElmer, USA) was added into $100-\mu \mathrm{L}$ PBS containing $0.1 \mathrm{OD}_{540}$ of cells. The final concentration of the external $\mathrm{D}-\left[2-{ }^{3} \mathrm{H}\right]$ glucose was $0.46 \mu \mathrm{M}$. The uptake of radiolabelled substrate was stopped at $180 \mathrm{~s}$ by rapidly filtering the solution through a $0.22-\mu \mathrm{m}$ pore-size membrane (Millipore, USA). The filter membranes were immediately washed with $2-\mathrm{mL}$ icecold PBS, solubilized with $500 \mu \mathrm{L}$ Optiphase HISAFE 3 (PerkinElmer) and used for liquid scintillation counting on a MicroBeta JET instrument (PerkinElmer). Microalgae cells without $\mathrm{D}-\left[2-{ }^{3} \mathrm{H}\right]$ glucose were used as a negative control. All counter-flow assays were performed at $25{ }^{\circ} \mathrm{C}$ and repeated at least three times. The error bars represent the standard deviations from three replicates.

\section{Determination of starch, lipid and protein}

A. protothecoides cells were cultured as described in methodology and collected at $120 \mathrm{~h}$. The total cellular lipid was measured using the procedures described by Jia et al. [41]. The protein has been extracted according to the procedure as previously described by Gao et al. [42]. The concentration of soluble protein was determined by following the instructions of Bradford Protein Assay Kit (C503031, Sangon Biotech, China). A Starch Detection Kit (BC0700, Solarbio, China) was used to determine the starch contents.

\section{Transmission electron microscopy}

Auxenochlorella protothecoides cells were pretreated using a standard protocol, including dehydration, embedding and sectioning [14]. The analysis was performed at the microscope facility in the School of Life Sciences of Tsinghua University using a H7650B transmission electron microscope (Hitachi, Japan), as described previously [2].

\section{Quantitative proteomic analysis by 2D LC-MS/MS}

The quantitative proteomic analysis was conducted as described previously [43, 44]. Proteins were extracted from A. protothecoides cells cultured for 5 days in $\mathrm{MC}$ and $\mathrm{HC}$, respectively, which originally has the density of $\mathrm{OD} 540=0.1$. The extraction was performed using
8-M urea, and samples comprising $200 \mu \mathrm{g}$ of total protein were reduced and alkylated. Next, the proteins were digested with trypsin (Promega, Fitchburg, WI) at $37^{\circ} \mathrm{C}$ overnight. Tryptic peptides were desalted and labeled with the tandem mass tag (TMT, Thermo Waltham, MA, USA) according to the manufacturer's protocol. Labeled peptides from different samples were mixed together, desalted and separated using a Dionex UltiMate 3000 two-dimensional HPLC system (Thermo Fisher Scientific, USA). In the first step, reversed-phase separation was performed on an HPLC system at $\mathrm{pH}$ 10.0, which yielded 47 fractions that were combined into 12 fractions after rotary evaporation, and then re-suspended in $0.1 \%$ formic acid for the next separation. For LC-MS/MS analysis, the TMT-labeled peptides were separated by HPLC at a lower $\mathrm{pH}$ via a 120 -min gradient elution at a flow rate of $0.250 \mathrm{~mL} / \mathrm{min}$. A Q-Extractive mass spectrometer was used in the data-dependent acquisition mode. Each full-scan mass spectrum in the OrbiTrap (300-1800 m/z, 70,000 resolution) was followed by 20 data-dependent MS/MS scans. The MS/MS spectra from each LC-MS/ MS run were searched against the UniProt $A$. protothecoides database using the SEQUEST search engine of Proteome Discoverer software. The false discovery rate was estimated and the cutoff score of $1 \%$ was accepted based on the decoy database. Relative protein quantification was performed using PD 1.4 software according to the manufacturer's instructions based on the intensity of six TMT reporter ions per peptide. The analysis was carried out in biological triplicates.

\section{Bioinformatic analysis}

The identified proteins with a Sum PEP Score of more than 5 , fold change of more than 1.3 times, and $p$-value of less than 0.05 were considered to be a differentially expressed proteins (DEP). The DAVID website was used to cluster the up- and downregulated proteins [27]. The clustering options include functional categories (UP KEYWORDS), gene ontology (GOTERM BP DIRECT, GOTERM CC DIRECT and GOTERM MF DIRECT) and protein domains (INTERPRO, PIR SUPERFAMILY and SMART).

The up- and downregulated proteins were next uploaded to KEGG Mapper for metabolic pathway enrichment. The upregulated proteins were marked in red, the downregulated protein were marked in blue, and the annotated proteins in $A$. protothecoides the protein database were marked green.

The online protein-protein interaction network database STRING (STRING: functional protein association networks) was used to query protein interactions. The Chlamydomonas reinhardtii protein-protein interaction network was used as a reference for protein 
homology-based analysis of the protein-protein interaction network of $A$. protothecoides based on the differentially expressed proteins with fold changes of more than 1.3 times. Visual interaction analysis of the protein-protein interaction network was performed using Cytoscape software.

\section{Measurements of the intracellular concentrations of NADH and $N A D^{+}$}

Auxenochlorella protothecoides cells were harvested during the exponential phase by centrifugation at $3000 \mathrm{~g}$ and $4{ }^{\circ} \mathrm{C}$ for $5 \mathrm{~min}$. Then, the cell concentration was adjusted to $\mathrm{OD}_{540}=1$ using ice-cold PBS (pH 7.4). Samples comprising $300 \mu \mathrm{L}$ of the normalized cell cultures were collected from each sample, and washed twice with PBS. The concentrations of $\mathrm{NAD}^{+}$(Nicotinamide adenine dinucleotide) and NADH (Nicotinamide adenine dinucleotide reduced form) were measured E2ND-100 $\mathrm{NAD}^{+} / \mathrm{NADH}$ Assay Kit purchased from Bioassay Systems (USA) according to the manufacturer's instructions.

\section{Statistical analysis}

The results were expressed as the means and standard deviations of triplicate experiments. Statistical analysis was conducted using GraphPad Prism 7.0 software. Student's $t$-test was used to assess the significance of differences between two sets of data, while multiple comparisons were performed using ANOVA. Differences with $p$-values of $<0.05$ were considered statistically significant.

\section{Supplementary information}

Supplementary information accompanies this paper at https://doi. org/10.1186/s13068-020-01787-9.

Additional file 1: Figure S1. TEM images of A. protothecoides cells from HC and MC. C: chloroplast; L: lipid bodies; S: starch granules. (A) Cells from the illuminated culture $(\times 1.2 \mathrm{~K})$; (B) Cells from the illuminated culture $(\times 3 \mathrm{~K})$; (C) Cells from the dark culture ( $\times 1.2 \mathrm{~K})$; (D) Cells from the dark culture $(\times 3 \mathrm{~K})$. Figure $\mathbf{S 2}$. Quantum yield $(\Phi)$ of PSII of $A$. protothecoides under the light and dark conditions with $0.5-\mathrm{g} / \mathrm{L}$ glycine. Figure S3. DEPS in photosynthesis. Figure S4. DEPs in fatty acid biosynthesis. Figure $\mathbf{S 5 .}$ DEPs in citrate cycle (TCA cycle). Figure $\mathbf{S 6}$. Schematic representation of a theoretical model of how glucose assimilation in A. protothecoides is negatively influenced by light.

Additional file 2: Table S1. Downregulated proteins of the comparative proteome. Table S2. Upregulated proteins of the comparative proteome.

\section{Abbreviations}

DEPs: Differentially expressed proteins; FAD: Flavin adenine dinucleotide; G3P: Glyceraldehyde-3-phosphate; HC: Heterotrophic culture; HPLC: High-performance liquid chromatography; LC-MS/MS: Liquid chromatography-tandem mass spectrometry; MC: Mixotrophic culture; OEC: Oxygen-evolving complex; OEE: Oxygen-evolving enhancer proteins; ORP: Oxidation-reduction potential; PBS: Phosphate buffer saline; PSI: Photosystem I; PSII: Photosystem II; PPI: Protein-protein interaction; PUFAs: Polyunsaturated fatty acids; RuBP: Ribulose bisphosphate; TCA: Tricarboxylic acid cycle; TEM: Transmission electron microscope; TMT: Tandem mass tag; VHL: Very high light.

\section{Acknowledgements}

We thank the Protein Chemistry Facility at the Center for Biomedical Analysis of Tsinghua University for sample analysis. We thank Dr. Yuling Chen, Mr. Changsheng Luo, Mr. Guanqin Huang for their helps in technical assistance or providing writing comments. We thank Dr. Danqiong Huang and Miss Sasha Balkaran for their help in revising manuscript.

\section{Authors' contributions}

$\mathrm{YB}, \mathrm{ZH}$ and $\mathrm{QW}$ conceived and designed the study. $\mathrm{YB}, \mathrm{JG}$ and $\mathrm{HZ}$ performed the experiments. YB, JG and $\mathrm{HZ}$ performed experimental data processing, analysis, and writing of the manuscript. YB, MA, ZH and HD reviewed and edited the manuscript. All authors read and approved the final manuscript.

\section{Funding}

This study was supported by the China National Key R\&D Project for Synthetic Biology (2018YFA0902500), the Guangxi Innovation Driven Development Special Fundation (Gui ke AA18242047), the Shenzhen Basic Research Project (JCYJ20180507182405562) and the Grant Plan for Demonstration City Project for Marine Economic Development in Shenzhen (No: 86) to Dr. Zhangli HU.

\section{Availability of data and materials}

All data generated or analysed during this study are included in this published article.

Ethics approval and consent to participate

Not applicable.

\section{Consent for publication}

All the authors agree to the submission and publication of this manuscript.

Competing interests

The authors declare that they have no competing interests.

\section{Author details}

1 Guangdong Technology Research Center for Marine Algal Bioengineering, Guangdong Key Laboratory of Plant Epigenetics, College of Life Sciences and Oceanography, Shenzhen University, Shenzhen 518060, People's Republic of China. ${ }^{2}$ Key Laboratory of Optoelectronic Devices and Systems of the Ministry of Education and Guangdong Province, College of Optoelectronic Engineering, Shenzhen University, Shenzhen 518060, People's Republic of China. ${ }^{3}$ Key Laboratory of Industrial Biocatalysis of the Ministry of Education and Center for Synthetic and Systems Biology, School of Life Sciences, Tsinghua University, Beijing 100084, People's Republic of China. ${ }^{4}$ Shenzhen Key Laboratory of Marine Bioresource and Eco-Environmental Science, Longhua Innovation Institute for Biotechnology, Shenzhen University, Shenzhen 518060, People's Republic of China.

Received: 29 March 2020 Accepted: 12 August 2020

Published online: 18 August 2020

\section{References}

1. Munoz-Marin MD, Gomez-Baena G, Diez J, Beynon RJ, Gonzalez-Ballester D, Zubkov MV, Garcia-Fernandez JM. Glucose uptake in Prochlorococcus: diversity of kinetics and effects on the metabolism. Front Microbiol. 2017:8:327.

2. He X, Dai JB, Wu QY. Identification of sporopollenin as the outer layer of cell wall in microalga Chlorella protothecoides. Front Microbiol. 2016;7:1047.

3. Patel AK, Joun JM, Hong ME, Sim SJ. Effect of light conditions on mixotrophic cultivation of green microalgae. Biores Technol. 2019;282:245-53.

4. Lv JP, Zhao F, Feng J, Liu Q, Nan FR, Liu XD, Xie SL. Transcriptomic analysis reveals the mechanism on the response of Chlorococcum sp. GD to glucose concentration in mixotrophic cultivation. Bioresour Technol. 2019;288:121568

5. Subramanian G, Yadav G, Sen R. Rationally leveraging mixotrophic growth of microalgae in different photobioreactor configurations for reducing the carbon footprint of an algal biorefinery: a techno-economic perspective. RSC Adv. 2016;6:72897-904. 
6. Morales-Sanchez D, Martinez-Rodriguez OA, Martinez A. Heterotrophic cultivation of microalgae: production of metabolites of commercial interest. J Chem Technol Biotechnol. 2017;92:925-36.

7. Manzoor M, Ahmad QUA, Aslam A, Jabeen F, Rasul A, Schenk PM, Qazi I. Mixotrophic cultivation of Scenedesmus dimorphus in sugarcane bagasse hydrolysate. Environ Prog Sustain Energy. 2019;39:e13334.

8. Zaslavskaia LA, Lippmeier JC, Shih C, Ehrhardt D, Grossman AR, Apt KE. Trophic obligate conversion of an photoautotrophic organism through metabolic engineering. Science. 2001;292:2073-5.

9. Kanno M, Carroll AL, Atsumi S. Global metabolic rewiring for improved $\mathrm{CO}_{2}$ fixation and chemical production in cyanobacteria. Nat Commun. 2017:8:1-11.

10. Xiao YB, He X, Ma Q, Lu Y, Bai F, Dai JB, Wu QY. Photosynthetic Accumulation of Lutein in Auxenochlorella protothecoides after Heterotrophic Growth. Marine Drugs. 2018;16:283.

11. Xiao Y, Lu Y, Dai J, Wu Q. Industrial fermentation of Auxenochlorella protothecoides for production of biodiesel and its application in vehicle diesel engines. Front Bioeng Biotechnol. 2015;3:164.

12. Miao XL, Wu QY. Biodiesel production from heterotrophic microalgal oil. Biores Technol. 2006:97:841-6.

13. Gao CF, Wang Y, Shen Y, Yan D, He X, Dai JB, Wu QY. Oil accumulation mechanisms of the oleaginous microalga Chlorella protothecoides revealed through its genome, transcriptomes, and proteomes. BMC Genomics. 2014;15:582.

14. Xiong W, Gao CF, Yan D, Wu C, Wu QY. Double CO2 fixation in photosynthesis-fermentation model enhances algal lipid synthesis for biodiesel production. Biores Technol. 2010;101:2287-93.

15. Caporgno MP, Haberkorn I, Bocker L, Mathys A. Cultivation of Chlorella protothecoides under different growth modes and its utilisation in oil/ water emulsions. Bioresour Technol. 2019;288:121476.

16. Sim SJ, Joun J, Hong ME, Patel AK. Split mixotrophy: A novel cultivation strategy to enhance the mixotrophic biomass and lipid yields of Chlorella protothecoides. Bioresour Technol. 2019;291:121820.

17. Tamoi M, Miyazaki T, Fukamizo T, Shigeoka S. The Calvin cycle in cyanobacteria is regulated by $C P 12$ via the $N A D(H) / N A D P(H)$ ratio under light/ dark conditions. Plant J. 2005:42:504-13.

18. He DL, Damaris RN, Fu JL, Tu JX, Fu TD, Xi C, Yi B, Yang PF. Differential molecular responses of rapeseed cotyledons to light and dark reveal metabolic adaptations toward autotrophy establishment. Front Plant Sci. 2016;7:988.

19. Zhao L, Dai J, Wu Q. Autophagy-like processes are involved in lipid droplet degradation in Auxenochlorella protothecoides during the heterotrophy-autotrophy transition. Front Plant Sci. 2014;5:400.

20. de Winter L, Cabanelas ITD, Martens DE, Wijffels RH, Barbosa MJ. The influence of day/night cycles on biomass yield and composition of Neochloris oleoabundans. Biotechnol Biofuels. 2017:10:104.

21. Krugel U, Veenhoff LM, Langbein J, Wiederhold E, Liesche J, Friedrich T, Grimm B, Martinoia E, Poolman B, Kuhn C. Transport and sorting of the Solanum tuberosum sucrose transporter SUT1 is affected by posttranslational modification (vol 20, pg 2497, 2008). Plant Cell. 2009;21:4059-60.

22. Adesanya VO, Davey MP, Scott SA, Smith AG. Kinetic modelling of growth and storage molecule production in microalgae under mixotrophic and autotrophic conditions. Biores Technol. 2014;157:293-304.

23. Zheng YT, Quinn AH, Sriram G. Experimental evidence and isotopomer analysis of mixotrophic glucose metabolism in the marine diatom Phaeodactylum tricornutum. Microb Cell Fact. 2013;12:1-17.

24. Wu C, Xiong W, Dai J, Wu Q. Genome-based metabolic mapping and ${ }^{13} \mathrm{C}$ flux analysis reveal systematic properties of an oleaginous microalga Chlorella protothecoides. Plant Physiol. 2015;167:586-99.

25. Sosa-Hernandez JE, Rodas-Zuluaga LI, Castillo-Zacarias C, Rostro-Alanis M, de la Cruz R, Carrillo-Nieves D, Salinas-Salazar C, Fuentes Grunewald C, Llewellyn CA, Olguin EJ, et al. Light intensity and nitrogen concentration impact on the biomass and phycoerythrin production by Porphyridium purpureum. Mar Drugs. 2019;17:460.

26. Lu Y, Dai JB, Wu QY. Photosynthesis-fermentation hybrid system to produce lipid feedstock for algal biofuel. Environ Technol. 2013;34:1869-76.

27. Huang DW, Sherman BT, Lempicki RA. Systematic and integrative analysis of large gene lists using DAVID bioinformatics resources. Nat Protoc. 2009;4:44-57.

28. Gutle DD, Roret T, Hecker A, Reski R, Jacquot JP. Dithiol disulphide exchange in redox regulation of chloroplast enzymes in response to evolutionary and structural constraints. Plant Sci. 2017;255:1-11.

29. Buchanan BB, Balmer Y. Redox regulation: a broadening horizon. Annu Rev Plant Biol. 2005;56:187-220.

30. Szklarczyk D, Gable AL, Lyon D, Junge A, Wyder S, Huerta-Cepas J, Simonovic M, Doncheva NT, Morris JH, Bork P, et al. STRING v11: protein-protein association networks with increased coverage, supporting functional discovery in genome-wide experimental datasets. Nucleic Acids Res. 2019;47:D607-D613613.

31. Kanehisa M. Post-genome informatics. Oxford; New York: Oxford University Press; 2000.

32. Wang LX, Liang WY, Xing JH, Tan FL, Chen YY, Huang L, Cheng CL, Chen W. Dynamics of chloroplast proteome in salt-stressed mangrove Kandelia candel (L.) Druce. J Proteome Res. 2013;12:5124-36.

33. Zhang MH, Li GW, Huang W, Bi T, Chen GY, Tang ZC, Su WA, Sun WN. Proteomic study of Carissa spinarum in response to combined heat and drought stress. Proteomics. 2010;10:3117-299.

34. Forster B, Mathesius U, Pogson BJ. Comparative proteomics of high light stress in the model alga Chlamydomonas reinhardtii. Proteomics. 2006;6:4309-20.

35. Heide $\mathrm{H}$, Kalisz HM, Follmann $\mathrm{H}$. The oxygen evolving enhancer protein 1 (OEE) of photosystem II in green algae exhibits thioredoxin activity. J Plant Physiol. 2004;161:139-49.

36. Slewinski TL, Braun DM. Current perspectives on the regulation of wholeplant carbohydrate partitioning. Plant Sci. 2010;178:341-9.

37. Geigenberger $P$, Kolbe A, Tiessen A. Redox regulation of carbon storage and partitioning in response to light and sugars. J Exp Bot. 2005:56:1469-79.

38. Porra RJ. The chequered history of the development and use of simultaneous equations for the accurate determination of chlorophylls $\mathrm{a}$ and $\mathrm{b}$. Photosynth Res. 2002;73:149-56.

39. Zheng YH, Li Z, Tao M, Li JC, Hu ZL. Effects of selenite on green microalga Haematococcus pluvialis: Bioaccumulation of selenium and enhancement of astaxanthin production. Aquat Toxicol. 2017;183:21-7.

40. Deng D, Sun PC, Yan CY, Ke M, Jiang X, Xiong L, Ren WL, Hirata K, Yamamoto M, Fan SL, Yan N. Molecular basis of ligand recognition and transport by glucose transporters. Nature. 2015;526:391.

41. Jia B, Xie XF, Wu M, Lin ZJ, Yin JB, Lou S, Huang Y, Hu ZL. Understanding the functions of endogenous DOF transcript factor in Chlamydomonas reinhardtii. Biotechnol Biofuels. 2019;12:1-13.

42. Gao Y, Xiong W, Li XB, Gao CF, Zhang YL, Li H, Wu QY. Identification of the proteomic changes in Synechocystis sp. PCC 6803 following prolonged UV-B irradiation. J Exp Bot. 2009:60:1141-54.

43. Liu Y, Yang F, Li SY, Dai JB, Deng HT. Glutaredoxin deletion shortens chronological life span in Saccharomyces cerevisiae via ROS-mediated Ras/ PKA activation. J Proteome Res. 2018;17:2318-27.

44. Gu LX, Chen YL, Wang QT, Li XJ, Mi KX, Deng HT. Functional characterization of sirtuin-like protein in Mycobacterium smegmatis. J Proteome Res. 2015;14:4441-9.

\section{Publisher's Note}

Springer Nature remains neutral with regard to jurisdictional claims in published maps and institutional affiliations. 